\title{
Hegemonías discursivas en el relato transmediático de la crisis: narrativas digitales $v s$ periodísticas
}

\author{
Miguel Álvarez-Peralta* \\ miguelalvarezperalta@ccinf.ucm.es
}

(Abstracts y palabras clave al final del artículo)

Enviado: 22 de abril de 2013

Evaluado: 1 de julio de 2013

Aceptado: 19 de julio de 2013

\section{INTRODUCCIÓN Y DELIMITACIÓN DEL ANÁLISIS}

El presente artículo afronta la transmedialidad como herramienta para la evaluación del impacto que las narrativas mediáticas hegemónicas en los diarios de referencia tienen sobre la construcción de la crisis económica en el espacio público digital. Como es habitual en estudios transmediáticos, se rastrea la evolución que ciertas narrativas concretas popularizadas a través de medios de masas sufren en las redes sociales más populares, siguiendo la idea de que el análisis de sus alteraciones, expansión, duración y ramificaciones, constituye una vía de acceso válida a las complejas dinámicas discursivas de la cultura digital de masas, y por tanto podría revelar algunas de las divergencias y similitudes entre el espacio público digital y el espacio mediático informativo.

Con esta intención, analizaremos primeramente los principales rasgos narrativos del relato con que uno de los principales diarios españoles enmarcó la crisis durante su origen, para después estudiar su carácter transmediático al contrastarlo con los que exhiben las micronarrativas dominantes en la que cada vez más se revela como una de las redes sociales de mayor impacto: Twitter. Tomaremos por caso de estudio el periódico El País por tratarse del diario generalista de pago con mayor tirada en España.

El evento a analizar será el arranque de la crisis económica, por lo que nos centraremos en las primeras dos semanas tras el derrumbe financiero de septiembre de 2008, considerado como el pistoletazo de salida del caos bursátil que a su vez justificó la adopción de planes de rescate bancario en muchos países. Para restringir el

\footnotetext{
* Profesor Ayudante en el Departamento de Periodismo de la Universidad de Castilla-La Mancha (UCLM). Visiting Fellow en el Departamento de Romance Languages de la Faculty of Arts and Sciences de Harvard University (Boston, USA) y director de la publicación digital "El Observador de Castilla" (observador.info).
} 
corpus y centrar nuestro análisis, este se limitará al discurso de portada durante la quincena en cuestión, asumiendo el supuesto de que las funciones de resumen, focalización, priorización y organización de los eventos del día que la portada cumple, hacen de su contenido una suerte de línea editorial implícita, de mayor relevancia incluso que la editorial explícita en páginas interiores.

\section{METODOLOGÍA}

Para analizar este discurso periodístico, además de apoyarnos en el aparato conceptual habitual del análisis semiótico narrativo, y en concreto en la obra de Greimas y Courtés (Courtés 1980), se tomará también como materia de interpretación los datos resultantes del análisis lexicométrico que sobre este mismo corpus hemos realizado en trabajos anteriores. Vincularemos de este modo análisis de contenido léxico y análisis narrativo, lo que cada vez resulta menos infrecuente en los estudios de comunicación de masas contemporáneos. Esta triangulación metodológica, sin embargo, obliga a salvar adecuadamente el riesgo de eclecticismo epistemológico que entraña, básicamente renunciando a reivindicar cualquier supuesta objetividad fáctica en el sentido positivista para las conclusiones de la descripción argumentada que haremos de nuestra lectura del corpus, pese a que sea también lectura de unos datos léxicos obtenidos, estos sí, mediante la metodología objetivadora del análisis de contenido asistido por ordenador.

Así pues, tomando prestados algunos elementos de la mencionada gramática narrativa greimaseana, pasamos a describir los rasgos principales del relato con que el diario El País da cuenta de la llamada "quincena negra", cuando la caída de Lehman Brothers comienza a arrastrar a grandes entidades de todo el mundo tras de sí y siembra el pánico en las principales bolsas de valores del planeta. Como hemos apuntado, la narratividad ocupa un rol privilegiado en los procesos psicológicos a la hora de reconstruir el mapa mental de nuestra propia experiencia vital. Más allá de este rol reconocido desde la psicología constructivista, el análisis a través del esquema actancial pone de manifiesto cómo toda estructura narrativa está sustentada en "sistemas de valores" socialmente discutidos (Courtés, 1997). En palabras recientes de Massimo Leone, las narraciones periodísticas no son sino la puesta en escena de relaciones y conflictos de valores, no solamente en el sentido de que disponen los simulacros narrativos que nos permiten vivir estos conflictos en primera persona, sino también en el sentido de que nos empujan a tomar posición en ellos, a vivir la experiencia de un disgusto casi físico ante la necesidad de dar vida al mal y sus personajes en la animación del relato, y a un gozo casi corpóreo ante el alivio de deslizarnos dentro de los personajes que sobre el mal triunfan (Leone, 2013).

Siguiendo esta idea, haremos hincapié en identificar a los sujetos principales del relato, e indagar sus acciones características para analizar el modo en que el texto los caracteriza y los asocia a unos valores y expectativas determinados. Nos interesa por tanto resaltar aquel que el análisis estadístico revela como protagonista del relato, y a partir de sus relaciones deducir los demás a partir de las posiciones postuladas por el esquema actancial greimaseano. 
Si por algo interesa el recurso a este modelo teórico, resultante del meta-análisis que Greimas y Courtés hacen del formalismo ruso, es precisamente por lo que tiene de exhaustivo y universal, su capacidad para aprehender estructuras subyacentes a la mayor parte de las narrativas populares, incluyendo por ejemplo casi todo el cine hegemónico del siglo pasado. Se trata de una estructura identificable en prácticamente cualquier modelo canónico de narración moderna. Aunque, obviamente, la aparente exhaustividad o universalidad del esquema no es tal, es bien cierto que recoge perfectamente el tipo de relato causal, individualista (i.e. centrado en un protagonista, individual o colectivo), activo (dotado de una misión trascendente que ejecutar), dicotómico (opuesto a la acción de un antagonista que representa el mal), finalista (regido por un conflicto principal y orientado a una acción resolutiva del mismo) y moralizante (que pone en escena una serie de juicios éticos y valores morales culturales, asociados a objetos de deseo) que durante siglos ha caracterizado las narrativas populares de mayor difusión en Occidente y también, y esta es la hipótesis subyacente a su elección como herramienta analítica para el relato informativo, a la forma simplificada en que nos contamos y memorizamos la realidad que nos rodea. Si de hecho, como la psicología narrativa propone, es a partir de la reconstrucción de relatos causales similares a estos como tendemos a leer la realidad, el esquema greimaseano puede interpretarse como dispositivo cognitivo predilecto que estructura nuestra manera de entender cada hilo narrativo, organizando así los eventos del mundo de los que tenemos conocimiento, entre ellos, y especialmente, las construcciones mediáticas de realidades a las cuales no tenemos acceso directo. Es con esta filosofía que tratamos de reconstruir el esquema actancial, y no con intención de aprehender una supuesta "estructura profunda" inmanente al relato, sino más bien para obtener un arquetipo narrativo del mismo que nos permita contrastarlo con los producidos por otras narrativas alternativas de la crisis.

\section{LOS PERSONAJES DE LA CRISIS: EL ESQUEMA ACTANCIAL DOMINANTE}

Aclarados objetivo y método, procedemos a la interpretación de los resultados del análisis lexicométrico. Como muestra la tabla I, de frecuencias léxicas lematizadas a partir del corpus, los términos más frecuentes revelan de una parte la extrema importancia que El País asigna a este suceso (la palabra crisis aparece en este periodo más de dos veces por portada, una cifra absolutamente extraordinaria que indica una priorización desmesurada); de otra parte, aparecen dos personajes cuya frecuencia es aún mayor que la del propio contexto de crisis: la banca y el presidente.

\begin{tabular}{|l|l|}
\hline Banc & 46 \\
\hline Presiden & 35 \\
\hline Crisis $~$ & 32 \\
\hline
\end{tabular}

Tabla I. Tabla de frecuencias léxicas del corpus, lematizadas mediante el software J-Freq 
Tenemos a dos sujetos hiper-representados, de lo que cabe deducir que jugarán papeles principales. Si preguntamos al software analítico cuáles son los verbos (acciones) más representados en el corpus, nos devolverá los términos "evitar" y "salvar". Al requerir los objetos directos e indirectos de estos verbos - lo que es evitado o salvado en el relato-, los términos resultantes forman unos haces léxicos sorprendentemente compactos en términos semánticos. Lo evitado: crisis, colapso, desastre, quiebra, caos total, descalabro total, arrastramiento. Lo salvado: empresas, empresas privadas, bancos, compañías, aseguradoras, economía capitalista, entidades financieras, medidas (de rescate).

Estas isotopías lo son en un doble sentido: por un lado están compuestas por términos que ocupan, como dice la etimología griega de la palabra, un mismo lugar sintáctico; por otro lado, según la definición del propio Greimas, forman conjuntos de categorías semánticas que posibilitan la lectura uniforme del relato, permitiendo así eliminar ambigüedades en cada enunciado aislado y perseguir una lectura global. Tenemos así al destinatario de la acción principal, quien debe ser salvado, bajo la categoría de la economía privada en general y la banca financiera en particular. Dicho destinatario se ve amenazado por una acción maligna despersonalizada, difusa, terrible pero de carácter cuasi-natural, lo que debe ser evitado: la crisis (equiparada a la quiebra). A través de estas operaciones, los números arrojan un primer esquema narrativo, confirmado por una lectura contextualizada del corpus. Podría resumirse en la siguiente frase: la quiebra amenaza a la banca financiera, y con ella arrastra a toda la economía capitalista, por lo que el presidente (Bush) entra en acción para salvarlos y evitar el mal de la crisis.

Tenemos ya un Anti-Objeto claro como centro de nuestro esquema actancial, lo no deseado, la amenaza de desastre y descalabro total: la crisis. A este corresponde un Objeto de Deseo, su opuesto, que denominaremos estabilidad financiera, lo que debe ser alcanzado porque su presencia niega la del Anti-Objeto. La oposición Objeto vs. Anti-Objeto introduce automáticamente la misión del Héroe: alejar este último del Mundo y procurar el acercamiento del Objeto. Al asumir esta misión, se postula como protagonista de este relato la figura del presidente, quien por iniciativa propia "sale al rescate" con su propuesta de un "Plan de salvamento"1. Con esto queda configurado el llamado Eje del Deseo del esquema actancial, que relaciona al Sujeto (activo) con el Objeto (pasivo) con que debe entrar en conjunción: la estabilidad financiera (cuyo indicador serían en este caso unos índices bursátiles estables).

En relación con el Objeto, hemos situado también ya aquellos actantes amenazados por su ausencia, los Destinatarios de la acción del protagonista y principales interesados en el Objeto: las grandes empresas privadas aseguradoras, bancarias e hipotecarias. No obstante, una lectura detallada revela un interesante detalle sobre este Destinatario: tras ellas se sitúa un subsiguiente nosotros difuso - los que "íbamos al descalabro total"2_, la economía y toda la nación, sufridores colaterales de las desgracias del empresariado. Por eso el desvío de fondos públicos para sociali-

${ }^{1}$ El País, Madrid, Grupo Prisa, 20 de septiembre de 2008, p. 1.

2 El País, Madrid, Grupo Prisa, 21 de septiembre de 2008, p. 1. 
zar pérdidas privadas se denomina en este relato "El Plan de EE. UU." 3 . Este actante ambiguo, flexible, puede expandirse hasta englobar a la sociedad entera. Es precisamente este impreciso nosotros el que justifica narrativamente la potente intervención de los poderes públicos. A través de esta construcción discursiva, El País (y demás diarios mainstream en España), asumieron acríticamente la estrategia narrativa del gobierno de EE. UU. durante la operación de socialización de pérdidas bancarias a que hemos asistido en los últimos años, que ha enfrentado no pocas críticas entre expertos economistas, así como desde la ciudadanía.

En todo relato clásico, la existencia de un Destinatario de la acción presupone formalmente la de un Destinador que es su hiperónimo, le es anterior, pero igualmente interesado en alcanzar un estado de conjunción entre Destinatario y Objeto, para lo que invoca y legitima la acción del Sujeto protagonista. Es el rey que encarga al héroe liberar a la princesa y le premia con su mano en caso de éxito. Sin embargo, en el escenario dibujado por las portadas de El País, no aparece explicitado Destinador alguno. No hay un sujeto que responda a las siguientes preguntas: ¿Quién ha lanzado la trama principal colocando al sujeto en la necesidad de obrar? ¿Quién finalmente sancionará su acción reconociendo su éxito o fracaso? ¿Con quién establece este doble contrato el protagonista? (Courtés, 1997) Sin embargo, que no figure explícitamente no significa que no exista un juez sancionador de la misión. Para funcionar narrativamente como misión, es necesario que alguien juzgue su éxito. Se trata de un sujeto estratégicamente omitido, un actante elíptico, implícito, cuyo nombre ha de ser deducido por el lector. La ocultación del Destinador en esta organización del relato no es baladí: tiene de hecho un fuerte carácter ideológico. La intervención se nos presenta así como de una necesidad evidente, no hace falta que nadie la encargue y ordene, son las mismas circunstancias del mundo las que llaman automáticamente a intervenir (rescatar). Curiosamente esto no sucedió meses antes, cuando el índice de desahucios crecía a más del $100 \%$ en Estados Unidos. Si debemos deducir el Destinador del relato, deberemos descartar entidades análogas a "la opinión pública" o "los votantes", como sería de suponer en un sistema democrático, porque de facto el relato reconoce la impopularidad de este plan — " $45 \%$ de la ciudadanía rechaza la intervención"4_. Podría considerarse a las propias empresas o los índices bursátiles como solicitantes de la intervención, y también como aquellos que finalmente evaluarán el resultado, pero resistiremos la tentación de solventar el dilema cayendo en el fácil sincretismo DestinadorDestinatario, porque el esquema actancial aclara que es característico del Destinador, a diferencia del Sujeto y del Destinatario, no correr el riesgo de perecer en la acción. De otro modo, nunca podría sancionar el fracaso de la misma.

Para resolver esta dificultad recurriremos a ciertas convenciones de género, presentes a lo largo de todo este relato. Efectivamente, existe todo un género de relatos donde no hay Destinador explícito para la misión del Héroe, precisamente aquellos donde el Héroe lo es en sentido absoluto: las aventuras de superhéroes. En ellas, nos-

${ }^{3}$ El País, Madrid, Grupo Prisa, 26 de septiembre de 2008, p. 1.

${ }^{4}$ El País, Madrid, Grupo Prisa, 27 de septiembre de 2008, p. 1. 
hace falta que nadie ordene a Superman o a Batman intervenir para salvar al Mundo. Conscientes de sus poderes especiales, se ven obligados a aceptar el peso histórico de su responsabilidad, ponerse al servicio del Bien y el orden sin esperar nada a cambio. Claro que existe sancionador elíptico de semejantes misiones absolutas, un juez colectivo implícito que se corresponde con los sujetos absolutos mencionados, una entidad abstracta organizable como juego de muñecas rusas en creciente orden de globalidad: solamente la Nación, el Mundo, e incluso Dios, la Historia, y la Humanidad como su sujeto, pueden juzgar las proezas históricas - "La historia me absolverá", alegaba Fidel Castro en su juicio tras el fracaso de su asalto al Cuartel Moncada- Tenemos entonces que en este discurso el rol de Destinador es ocupado por un no-sujeto, un actante global de límites abiertos nucleado en torno a un nosotros trascendente, lo que resulta perfectamente coherente con la categoría de superhéroe que reviste el protagonista. Es su propia condición de poderoso, y su amor por el Mundo y la Humanidad, lo que estimula su hacer: no necesita un Destinador concreto ni una orden, él es el bien en sí mismo, revelado en su acción contra el mal en estado puro, destilado, sin necesidad de investiduras antropomorfas que entorpezcan su identidad concretándola.

Estas categorías concéntricas macrodiscursivas (Nación, Mundo, Historia, Humanidad), nucleares para el imaginario occidental, llevan al protagonista a arrogarse la responsabilidad de actuar. Así se entiende en el nivel diegético de nuestro análisis, pero cabría considerar, intersecando un plano extra-diegético, a la propia Prensa - y en concreto a este diario - como entidad que reconoce implícitamente al protagonista en disposición de actuar y otorga a su plan la cualidad de intervención legítima y necesaria. De facto, es el diario quien finalmente sanciona en el nivel de la diégesis el fracaso del protagonista ${ }^{5}$. Con estos elementos, añadimos al esquema el llamado Eje de la Comunicación, que representa la relación por la cual el Destinador pretende hacer llegar al Destinatario el Objeto a través de la acción del Sujeto protagonista.

Por último, para completar la estructura actancial canónica, resta organizar los demás actantes involucrados en tanto que adyuvantes o entorpecedores de la acción principal. Entre los primeros, identificamos al resto de poderes públicos estadounidenses (el Tesoro, la Reserva Federal, el FBI, etc.), que realizan intervenciones tempranas o nacionalizaciones obligadas por la amenaza de caos, asumiendo las órdenes y objetivos del protagonista (como se puede comprobar en las portadas de El País de los días 16, 17, 18, 21, 23 y 29 de septiembre de 2008). En cuanto a los oponentes, nos topamos de nuevo con la no representación explícita como opción estratégica que revela una construcción fuertemente ideológica del evento. Por un lado, es coherente que en el texto no se mencione explícitamente la figura de un antagonista. ¿Quién iba a ser tan malvado de desear el Anti-Objeto "caos" para todos nosotros? Los comunistas hace tiempo que fueron derrotados, el terrorismo internacional organizado no tiene nada que ver con este peligro, no hay ningún dictadorzuelo o eje del mal susceptible de ser públicamente señalado como culpable de esta amenaza. No

${ }^{5}$ El País, Madrid, Grupo Prisa, 30 de septiembre de 2008, p. 1. 
existe un ellos acorde a un nosotros tan global. Descartaremos considerar como oponentes a otro de los actantes representados en el relato: aquellas empresas privadas «investigadas» como posibles causantes de la catástrofe por su irresponsabilidad ${ }^{6}$, dado que estas realmente no se oponen a la acción principal del héroe: ciertamente han pagado ya su error pereciendo, o bien son destinatarias de la acción de salvamento.

Sólo un sujeto despersonalizado, un no-sujeto puede ejercer tan malvado rol y exhibir tanta capacidad de destrucción: la cólera de la Naturaleza, el "terremoto", el "huracán", el "seísmo", la "tormenta", castigos de una Diosa Economía — la Pachamama del hombre blanco- a los pecados de algunas empresas financieras, que amenaza ahora a justos como a pecadores con su diluvio universal, si el héroe no lo impide. Este es el indeterminado sujeto que envía el caos: la Economía como Leviatán indomable contra el que sólo el héroe (armado de fondos públicos) puede batallar. Se trata de un ente activo que "amenaza", "golpea", "cruza el atlántico", "invade" y "provoca el pánico" (fórmulas todas tomadas de portadas de El País durante esta quincena negra). La figura de un actante global difuso e indeterminado para el rol de Antagonista, resulta coherente y sirve de contrapeso para un Destinador de idénticas características, ambos ambiguos, inconcretos e infrarrepresentados, cuya oposición remite implícitamente al esquema del enfrentamiento entre el bien y el mal, tan común al imaginario occidental de raíces cristianas. El relato recoge también, aunque marginalmente, otro oponente que no es un Anti-Sujeto propiamente dicho, no encarna el mal. Se trata más bien de un adversario circunstancial, casi inconsciente, que por inocencia o torpeza se opone a la intervención salvadora, recogido en fórmulas como "el $45 \%$ de los ciudadanos", "los contribuyentes" o "un grupo de republicanos", instancias todas que podríamos considerar vinculadas a la categoría de Ciudadanía, opuestas (por el momento) a la intervención? Con esta categoría conformamos el Eje de la Acción y completamos el esquema actancial.

Formalizadas de esta manera las relaciones narrativas del relato, retornaremos al corpus para contrastar dicho esquema con los titulares de la quincena negra referidos al tópico de la crisis económica para así, en un movimiento de retorno inductivo-deductivo, confirmar o desechar su vigor exegético. La siguiente tabla recoge los 28 titulares en cuestión destacando en letra cursiva aquellos que adquirieron el peso máximo, las cinco columnas de portada, que coinciden con puntos de giro en el guión del relato, marcando sus diferentes capítulos.

${ }^{6}$ El País, Madrid, Grupo Prisa, 24 de septiembre de 2008, p. 1.

${ }^{7}$ El Pais, Madrid, Grupo Prisa, 26 de septiembre de 2008, p. 1. y 27 de septiembre de 2008, p. 1. 


\begin{tabular}{|c|c|c|}
\hline Día 15: & Wall Street se asoma al caos por el derrumbe de Lehman & 1 \\
\hline Día 16: & La mayor quiebra de la historia pone en jaque el sistema bancario de Wall Street & 2 \\
\hline \multirow[t]{2}{*}{ Día 17: } & EE. UU. nacionaliza la mayor aseguradora para evitar su quiebra & 3 \\
\hline & Solbes anuncia un Presupuesto de crisis con un déficit del 2\% & 4 \\
\hline Día 18: & La mayor hipotecaria británica se fusiona para evitar la quiebra & 5 \\
\hline Día 19: & EE. UU. creará una agencia estatal para auxiliar a los bancos en crisis & 6 \\
\hline Día 20: & Bush sale al rescate de Wall Street & 7 \\
\hline \multirow[t]{4}{*}{ Día 21: } & "Íbamos al descalabro total” (Bush) & 8 \\
\hline & "Si no se toman medidas, las empresas caerán una tras otra" (Presidente CEOE) & 9 \\
\hline & Diez días que cambiaron el capitalismo & 10 \\
\hline & "Para el mercado esto equivale a la caída del muro de Berlín" (Premio Nobel Economía) & 11 \\
\hline Día 22: & Bush apremia al Congreso para aprobar de urgencia el plan de rescate & 12 \\
\hline \multirow[t]{2}{*}{ Día 23: } & La desaparición de la banca de inversión pone fin a una era en Wall Street & 13 \\
\hline & Este otoño toca divorciarse menos & 14 \\
\hline \multirow[t]{2}{*}{ Día 24: } & La crisis también salpica a RTVE & 15 \\
\hline & El FBI investiga a Lehman, AIG, Fannie Mae y Freddie Mac & 16 \\
\hline \multirow[t]{3}{*}{ Día 25: } & McCain se escuda en la crisis para suspender la campaña & 17 \\
\hline & Zapatero garantiza en Nueva York la salud financiera de España & 18 \\
\hline & Ruiz-Gallardón paraliza todas las inversiones nuevas previstas en Madrid & 19 \\
\hline Día 26: & El plan de EE. UU. encuentra resistencia & 20 \\
\hline \multirow[t]{2}{*}{ Día 27: } & La crisis obliga a Solbes a presentar el Presupuesto más austero de la década & 21 \\
\hline & Bush negocia contra el reloj su plan de rescate & 22 \\
\hline Día 28: & Obama asume el liderazgo del cambio frente a McCain & 23 \\
\hline \multirow[t]{2}{*}{ Día 29: } & Tres países europeos toman el control del primer banco belga & 24 \\
\hline & Zapatero propone una reunión con Rajoy para pactar salidas a la crisis & 25 \\
\hline Día 30: & Fracasa el rescate de Wall Street & 26 \\
\hline \multirow[t]{2}{*}{ Día 1: } & Europa levanta defensas ante la crisis & 27 \\
\hline & El aumento del desempleo castiga el Presupuesto más austero & 28 \\
\hline
\end{tabular}

Tabla II. Titulares de la quincena negra referidos a la crisis económica (El País)

Efectivamente, los titulares número 1, 2, 3, 5, 6, 9, 13 y 24 confirman que los Destinatarios de la acción principal, quienes pasan apuros en esta historia, son en primer lugar las bolsas de valores como indicadores de la salud de las entidades que en ellos cotizan (aquellas que sufren "quiebra" y "fusiones", por lo que "caerán una tras otra» a menos que haya "rescates", "nacionalizaciones" o "inyecciones" que las ayuden). Tras ellas, aparece ese nosotros totalitario, los que "íbamos al descalabro total» (titulares 8 y 14). Ello justifica que el inicialmente llamado "plan Bush" reaparezca después como "el plan de EE. UU.", el proyecto de toda una nación (titular 20).

Los titulares 7, 8, 12 y 22 confirman el rol del Héroe, sujeto activo por excelencia que "sale al rescate", "apremia al congreso" y "negocia contrarreloj", aunque finalmente "encuentra resistencia" y "fracasa" junto a su plan. Como el esquema de Greimas predice, el candidato a héroe se identifica con su plan, su objetivo vital es el Objeto, de hecho lo que este discurso revaloriza no es el sujeto, en última instancia reemplazable, sino el plan en sí mismo. En la conclusión del primer acto del relato de crisis, el protagonista no se ha realizado como héroe, y se anticipa ya la toma del relevo por otros sujetos como "Obama" o "Europa" (titulares 23 y 27).

Como hemos señalado, la figura del Destinador es la gran ausente del discurso. Al no aparecer directamente, debemos deducirla a partir de la categorización del desastre 
como histórico y global - "mayor quiebra de la historia", "sistema bancario en jaque», "cambiar el capitalismo", "caída del muro", "fin de una era", etc.- por lo que ni siquiera hace falta que Bush decida actuar, sencillamente tiene la obligación de hacerlo, no hay otra alternativa, su hacer es un deber hacer, la representación favorece la idea de un compromiso con la Historia, independiente de la opinión ciudadana. Dado que es una acción necesaria, no requiere que el sujeto esté cualificado como héroe, de hecho no lo está, todo lo contrario, superó a duras penas su prueba calificante (las elecciones) pero encalló en la prueba decisiva (impopular gestión del desastre Katrina, la guerra contra Iraq, etc.) y en parte esto explica su fracaso final y su reemplazo por el líder de la oposición: la ciudadanía no era Destinador de esta misión, su contrato no estaba firmado con el electorado, que en realidad rechazaba este plan.

Finalmente, en el epílogo del relato y ante la debacle de la economía estadounidense por "irresponsabilidad" de sus políticos, que ceden a la "inconsciente" presión ciudadana, un nuevo nosotros erigido en protagonista provisional, Europa, actúa con responsabilidad y "levanta defensas ante la crisis". No olvidemos diferenciar entre la compleja y multiforme realidad de los hechos, y la linealidad de la causalidad construida del relato periodístico: ninguna de las portadas de los principales diarios españoles se hizo eco en modo alguno de esta supuesta adopción de medidas defensivas a nivel europeo. Es una mera construcción narrativa (a cinco columnas) de El País. Aspectos como este ponen de relieve el carácter sesgado e ideológico de esta construcción narrativa. Cuando el Congreso estadounidense rechaza democráticamente el plan de rescate, el diario se permite anunciar en portada que "Un riesgo de hecatombe se cernió ayer sobre toda la economía mundial"8. El diario emplea este lenguaje sensacionalista y prioriza así su intención de influir mediante el miedo en la opinión pública a favor de los rescates bancarios, por encima de consideraciones democráticas. De hecho, considera culpables a las instancias democráticas denunciando "el imprevisible daño económico que esta votación puede provocar" y declarándose "a la espera de saberse si existen mecanismos para corregirla". ¿Es la votación la que provoca el daño? ¿Tan evidente es que un resultado contrario lo hubiera evitado? ¿Acaso la inyección de un billón de dólares de gasto público no es en sí misma un daño? ¿Por qué debe "corregirse" una votación? Si tan evidente es que existía una opción correcta y otra incorrecta ¿para qué votar? Dejemos en suspenso los interrogantes que ha levantado nuestra lectura del corpus, y asomémonos ahora a otros relatos posibles donde quizá hallemos las claves de sus respuestas.

\section{OTRA CRISIS ES POSIBLE: NARRATIVAS TRANSMEDIÁTICAS ALTERNATIAS}

La mejor manera de apreciar hasta qué punto la línea narrativa establecida por el diario El País es una construcción discursiva sesgada respecto de la realidad extra-textual, como apuntaban los interrogantes anteriores, es contrastarla con los

${ }^{8}$ El País, Madrid, Grupo Prisa, 30 de septiembre de 2008, p. 1. 
relatos que a partir de esa misma realidad generan otros medios. Fijémonos en aquellos más críticos, que no comulgan con los planes de rescate bancario: el diario Público (hoy desaparecido) y el quincenal Diagonal.

La narrativa hegemónica tenía por objetivo naturalizar lo que en realidad es una opción ideológica, la adopción del punto de vista de los grandes capitales como sentido común generalizado, y la identificación de sus intereses como interés general. Es la doctrina neoliberal del crecimiento y la competitividad, que se apoya en ciertos mantras del mundo financiero, auténticas "callosidades ideológicas" impenetrables, axiomáticas, ajenas a todo razonamiento. Cuando el grado de hegemonía de una cosmovisión es tan amplio que toda construcción alternativa de la realidad aparece como marginal y utópica, acostumbrados ya a mirar el mundo desde la(s) ideología(s) dominante(s), a través de las metáforas impuestas por los grandes centros de producción de discursos, como unas gafas que muestran sin ser vistas, que permiten ver gracias a su transparencia, para reflexionar sobre estos mecanismos de dominación ideológica se hace necesaria una operación de extrañamiento, un ejercicio de toma de distancia ante lo cotidiano para preguntarse acerca de lo evidente y afirmar lo también evidente y sin embargo socialmente inapreciado: hay otras formas de narrar el mundo. En este sentido aportamos ejemplos de discursos alternativos, para, mediante el contraste, concluir la caracterización del relato El País como discurso intencionalmente sesgado.

Si prestamos atención a la cobertura que realiza el periódico de actualidad crítica Diagonal, en la portada de sus números 85 a 89 - corresponden a la misma quincena negra, a la que añadimos los tres números siguientes para alcanzar una muestra considerable - encontramos una construcción de la crisis fuertemente ideologizada en sentido opuesto, como explicitan la mayoría de sus titulares, que manifiestan unos criterios de relevancia divergentes, la emergencia de nuevas categorías y una tematización diferente de la misma cuestión:

\begin{tabular}{|c|c|}
\hline Periódico $n^{0}$ & Titulares de portada \\
\hline 85 & $\begin{array}{l}\text {-La riqueza de las grandes fortunas crece por sexto año. -El número de personas con más de } \\
\text { mil millones de dólares aumenta un } 5 \% \text { pese al desplome financiero. }\end{array}$ \\
\hline \multirow{3}{*}{86} & $\begin{array}{l}\text {-Intervencionismo estatal para salvar a los especuladores. -Socialismo para ricos, capitalismo } \\
\text { para pobres. }\end{array}$ \\
\hline & $\begin{array}{l}\text {-Los Estados acuden al rescate de empresas sin explicar las condiciones ni los plazos de } \\
\text { devolución. -La crisis hipotecaria de EE UU castiga a las familias de menos recursos. -El índice } \\
\text { de pobreza en el Estado español llega al } 20 \% \text {. }\end{array}$ \\
\hline & $\begin{array}{l}\text {-Los gobiernos abanderados de la no intervención salvan y nacionalizan las empresas en } \\
\text { quiebra después de décadas de enriquecimiento, especulación y prácticas abusivas. Prácticas } \\
\text { abusivas como las hipotecas subprime, que causan miles de desahucios en Estados Unidos, } \\
\text { sobre todo entre las familias con menos recursos. }\end{array}$ \\
\hline 87 & $\begin{array}{l}\text {-Recortes sociales // ¿Quién paga los platos rotos? -Con el fin del boom, las deudas de los } \\
\text { ayuntamientos recaen en los ciudadanos. }\end{array}$ \\
\hline \multirow{2}{*}{88} & $\begin{array}{l}\text {-Multinacionales // Una oportunidad para la reorganización y el mantenimiento de sus beneficios } \\
\text {-Despidos: la crisis como excusa }\end{array}$ \\
\hline & $\begin{array}{l}\text {-La cifra de paro se acerca cada vez más a los tres millones } \\
\text {-Las multinacionales despiden, pero sus cuentas continúan siendo positivas. }\end{array}$ \\
\hline 89 & $\begin{array}{l}\text {-La crisis también afecta a la salud mental. -La OMS prevé un aumento del estrés, depresiones } \\
\text { y otros desórdenes mentales, sobre todo entre los pobres. }\end{array}$ \\
\hline
\end{tabular}

Tabla III. Titulares sobre la crisis económica en las portadas del periódico Diagonal 
Saltan a la vista grandes diferencias en las estrategias de selección de sujetos relevantes en portada. Mientras en El País "la ciudadanía" o "los trabajadores" son una categoría infrarrepresentada, en este discurso constituyen el elemento central que orienta la selección narrativa. Diagonal huye de la metáfora del desastre natural tan reiterada por El País, priorizando en primera plana los que considera antecedentes ("después de décadas de enriquecimiento") o apuntando a las causas de la crisis ("crisis hipotecaria", "prácticas abusivas como las hipotecas subprime") y sus consecuencias directas para los trabajadores, los contribuyentes, las familias con menos recursos, o los pobres ("despidos", "pobreza", "estrés", "depresiones", "recortes sociales", "subida de impuestos", "deuda pública", etc.). Estos centros de interés son totalmente secundarios o inexistentes para la narrativa hegemónica.

Si en el discurso anterior advertíamos la presencia de un todos totalitario (el mundo, la sociedad, la economía, la nación), tras aquel nosotros-los-que-ibamos-aldescalabro que ocultaba las diferentes posiciones sociales en el reparto de beneficios - tanto de la especulación abusiva que ha llevado a la crisis como de las inyecciones planificadas - , esta narración se emplea para poner de relieve la imagen de una sociedad atravesada por fuertes divisiones clasistas entre "ricos" y "pobres", "especuladores" y "familias con pocos recursos", "empresas" y "ciudadanos".

Encontramos otro ejemplo de construcción de la crisis menos radicalizado pero también fuertemente antagonista en la realizada por el diario Público, comprometido con la búsqueda de un mercado de lectores desatendido por El País, tradicionalmente considerado "de izquierdas", y que se ubica en un punto del espectro político intermedio entre los dos anteriores. Su relato arranca el 14 de septiembre de 2008 construyendo un planteamiento narrativo directamente opuesto al dominante, con titulares como: "Del boom a la crisis: las inmobiliarias sólo han perdido un tercio de lo que ganaron", "Las más grandes siguen arrojando beneficios en el conjunto de los cinco últimos ejercicios. Dos de ellas han subido los sueldos de sus consejeros hasta un 75\% este mismo año"; y "El chantaje del ladrillo feroz".

Al esforzarse por mostrar los antecedentes de la supuesta crisis hipotecaria, elemento prácticamente obviado por El País, este diario denuncia abiertamente que las empresas hoy en crisis vienen exhibiendo un fuerte lucro en los últimos tiempos, anticipándose al "chantaje" que supone colocarse como víctimas de una crisis que ellas mismas han provocado, para ahora exigir su rescate. Reemplazan así la metáfora del desastre natural por la metáfora del pícaro o el avaro. En su crónica de la estafa, este diario ha dado cabida sistemáticamente a las distintas instancias de la ciudadanía: "manifestantes", "trabajadores" o "empleos perdidos"9 forman parte prioritaria de este relato.

Merece la pena reseñar la distinta importancia que ambos diarios dan al tema de crisis. Mientras en El País todas las portadas entre el día 15 y el 30 de septiembre mencionan el tema, en Público hay tres portadas que lo desconocen por completo y sólo es tema estrella en el 35\% de las portadas, frente al 59\% en El País. No debería sorprendernos esta diferente priorización: es coherente con la dependencia de $E l$

\footnotetext{
9 Público, Madrid, Grupo Mediapro, 16 de septiembre de 2008, p. 1.
} 
País respecto de entidades financieras, por lo que la política de rescates resulta vital para su propia supervivencia inmediata. Por ello acapara toda su atención. Prisa había vivido un proceso de financiaización a partir de su estrategia de crecimiento de "alto riesgo", con base en expectativas virtuales (Almirón, 2008), que le convirtió en el grupo mediático español más dependiente del crédito, con un "endeudamiento crónico" que en ese momento casi quintuplicaba su patrimonio, y que superaba tanto sus ingresos como su capitalización bursátil (Almirón, 2009). El tiempo ha confirmado la progresiva dependencia de Prisa respecto de entidades financieras, hasta el punto de incorporar a tres grandes representantes de fondos de inversión en su consejo de dirección (Almirón y Segovia, 2012). Esta creciente dependencia contribuye a explicar aquellas posiciones discursivas opuestas a las del diario Público respecto de las políticas de intervención, como demuestra la muy diferente manera en que estas son presentadas el día 20: "Bush sale al rescate de Wall Street" (El Pais) vs. "Las bolsas se dan un festín con dinero público" (Público); o el modo en que ambos recogen las exigencias de la patronal, que El País presenta como necesarias ( «Si no se toman medidas las empresas caerán una tras otra», el día 21), mientras Público las introduce de forma crítica y reflexiva: "Cambia el discurso neoliberal: la patronal pide ahora que intervenga el Estado" (día 18) o "Nueva vuelta de tuerca. Tras reclamar "un paréntesis en la economía de libre mercado', el presidente de la CEOE quiere abrir ahora otro en los derechos de los trabajadores" (día 26). Mientras el tono del relato hegemónico correspondía a una especie de thriller del superhéroe contra la amenaza natural, el del relato minoritario remitiría más bien al de un docudrama con vocación de denuncia social.

El contraste entre las estructuras contractuales, y los correspondientes «sistemas de valores» que sustentan (Courtes, 1997) ambos relatos de la intervención económica, determinan tonos narrativos muy diferentes (hazaña mítica $v s$. protesta) y evidencian cosmovisiones opuestas: desde el Héroe que asume su responsabilidad con la Historia para llevar la paz — en forma de estabilidad bursátil — a la Sociedad, hasta una Clase política que antidemocráticamente accede a las exigencias de las respectivas Patronales para pagar con fondos públicos la quiebra de sus Empresas a pesar de los beneficios anteriormente obtenidos por estas. La pregunta que trataremos de responder a continuación, para continuar con nuestra trayectoria transmediática, es cuál de estas dos narrativas opuestas ha tenido un mayor impacto a medio plazo en las redes sociales digitales, en qué medida han sido asumidas y reproducidas por los prosumidores, y qué variaciones han sufrido en su periplo transmediático a lo largo del tiempo.

\section{DE LA PRENSA A LA RED: RECEPCIÓN Y REPRODUCCIÓN DE LOS RELATOS DE CRISIS}

Para seguir la pista a estas narrativas en las redes digitales, e indagar las estrategias de recepción, asimilación, resistencia y resignificación de las mismas, primeramente vamos a delimitar las áreas del ciberespacio en que rastrearemos las trazas de la posible respuesta activa.

Debido al carácter semi-privado de Facebook, la red social digital por antonomasia, que imprime un fuerte sesgo a toda investigación realizada en su seno (y debi- 
do también a que tanto la página Facebook de El País como sus foros de comentarios no existían durante el periodo que tratamos), descartamos buscar aquí la recepción y re-mediación digital de este relato. Optaremos por observar la principal red social global de carácter público: Twitter. Los comentarios o tuits que en ella se escriben o "tuitean", quedan públicamente accesibles, no restringidos a los seguidores de cada autor. Esto, junto a la obligatoria brevedad de los tuits (140 caracteres), imprime a esta red su carácter particular, que diferencia sus usos de los de otras redes masivas (Facebook, Tuenti, N-1, etc.). Estas prácticas características otorgan a Twitter especial relevancia para estudios mediáticos en general y periodísticos en particular. Como algunos investigadores han destacado, los usos populares de Twitter se han extendido "hasta acoger una serie de actividades periodísticas, para-periodísticas, y cuasi-periodísticas", por lo que "se ha convertido en una pieza importante en la caja de herramientas tanto de los periodistas como de los investigadores en periodismo" (Bruns \& Burgess, 2011). Su soporte multimedia y orientación al uso a través de telefonía móvil, y su capacidad para generar comunidades de interés en tiempo real, mientras está ocurriendo un evento, explican su especial predisposición hacia el "periodismo ciudadano". Se ha convertido además en un foro de intercambio de enlaces o referencias mediáticas, donde los usuarios actúan como "brokers informativos", dedicados a reproducir, seleccionar, reunir, subrayar y comentar noticias, lo que le confiere un rol clave para la investigación en recepción del discurso periodístico. De hecho, es ya habitual observar resúmenes de las reacciones que los tuiteros muestran ante un evento, programa, o tópico de discusión planteado desde los medios de masas: Twitter opera así además como fuente que retroalimenta contenidos para los medios tradicionales.

Twitter impone fuertes restricciones técnicas que no enumeramos aquí por cuestión de espacio, pero que hacen referencia a la antigüedad y exhaustividad del conjunto de tuits consultables mediante la aplicación oficial de búsqueda. Esto "impide cualquier estudio académico que pretenda hacer seguimiento de actividades o intereses para muestras representativas" (Bruns \& Burgess 2011). Por ello, optaremos por observar las narrativas recogidas por Twitter a través de la aplicación de pago Twend.it, que recopila únicamente los tuits más retwitteados de cada jornada, organizados según su origen geográfico, lo que nos permitirá evaluar cuál de las narrativas anteriormente analizadas ha tenido mayor eco, años después, en la plaza digital correspondiente al marco español.

\section{MICRONARRATIVAS DE CRISIS EN TWITTER}

No tendría sentido tratar de replicar el análisis que hemos aplicado a las portadas de periódico, porque en este caso no se trata de una única fuente discursiva institucional, sino más bien de una enorme pluralidad de fuentes individuales puntuales que, en el mejor de los casos, se repiten en dos o tres ocasiones a lo largo del periodo estudiado, constituyendo entre todas ellas un macrodiscurso fragmentario, una suerte de mosaico heterogéneo en el que rastrearemos las tendencias dominantes en cuanto a rasgos equivalentes a los analizados en el caso de los periódicos. La herramienta Twend.it nos va a permitir revisar una serie de "palabras clave" —en el sentido laxo con que Raymond Williams las reivindica cuando escoge analizar "palabras significativas y vinculantes en 
ciertas actividades y su interpretación" a la vez que "indicativas de ciertas formas de pensamiento[...] que abren cuestiones de las cuales es preciso que todos seamos mucho más conscientes" (Williams, 2003:19) —, a lo largo del periodo que va de junio 2010 hasta noviembre de 2012, así como restringir los resultados al ámbito geográfico español y presentarlos por orden decreciente de impacto.

Si por ejemplo nos preguntamos de qué valores y características se inviste al actante social "Banco" en los tuits más populares de este periodo, cuál es su caracterización dominante, podemos introducir dicha palabra como término de búsqueda y observar la nube léxica asociada. ¿Se trata de una entidad representativa de "todos nosotros", como procuraba la narrativa analizada, y por tanto vinculada directamente al bien común? ¿Muestran los tuits más divulgados sentimiento alguno de solidaridad con la banca o preocupación por su supervivencia? ¿Tiene siquiera asociado un valor positivo o por el contrato recibe un tratamiento disfórico como ocurriera en las narrativas periodísticas minoritarias? Entre los veinte tuits más retuiteados del periodo examinado conteniendo la palabra "banco" encontramos los siguientes:

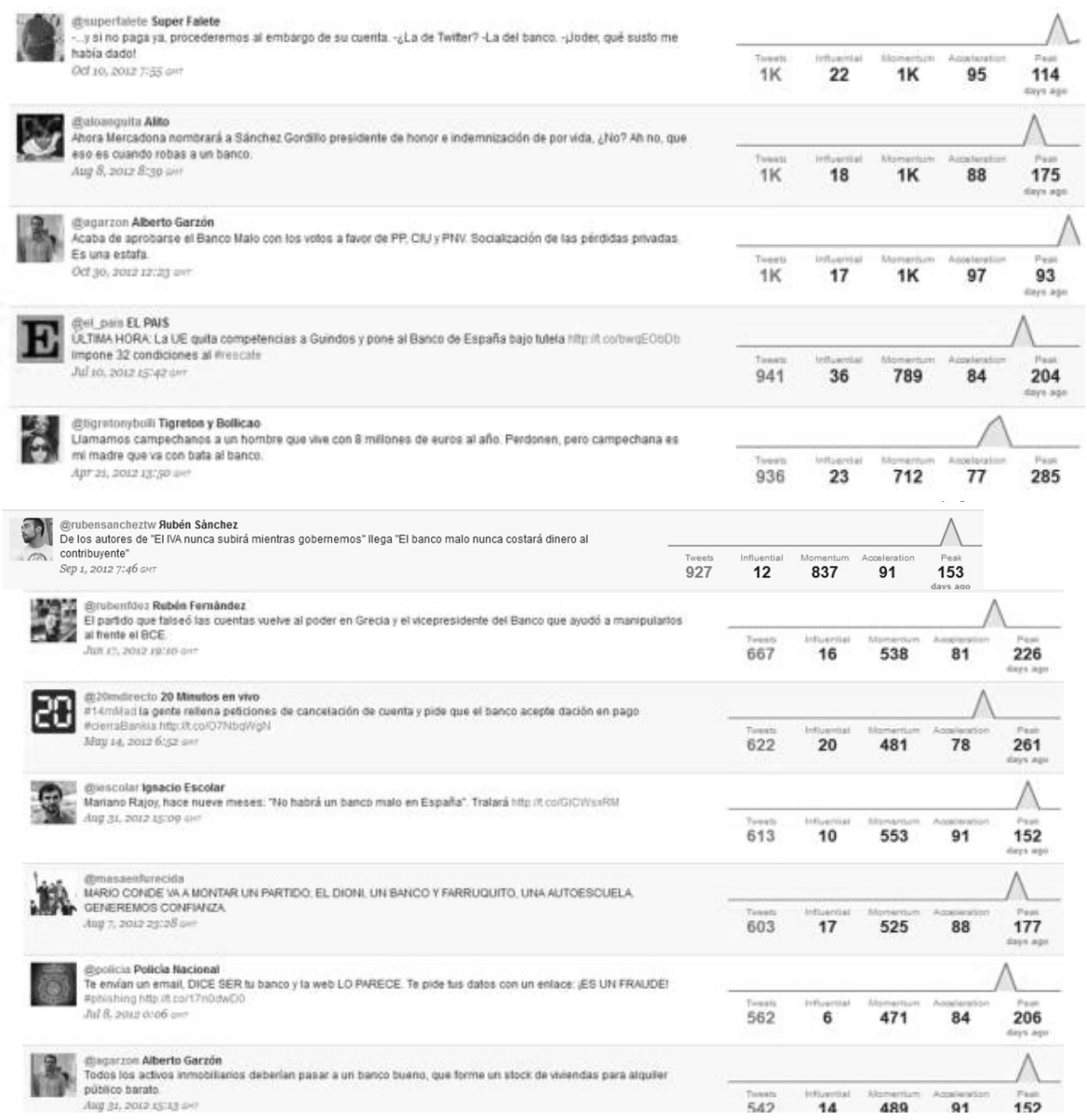

Tabla IV. Tuits más populares del periodo junio 2010 a noviembre 2012 conteniendo la palabra "banco" 
Como se puede apreciar, la representación no es caracterizable como positiva, ni goza de un tono eufórico, sino que predomina una perspectiva crítica o irónica, expresando un cierto desapego por medio de un humor ácido. La caracterización hegemónica de este actante en la red social es tendencialmente más próxima a las narrativas contrahegemónicas en el espacio público informativo de la prensa española. Las relaciones de hegemonía narrativa parecieran quedar invertidas en el salto transmediático del espacio público impreso al digital. La banca aparece aquí caracterizada como involucrada en estafas, boicoteada por sus usuarios, solapada al poder político y asociada a la corrupción. Incluso adquieren fuerte difusión colectiva ciertas propuestas alternativas al sistema bancario privado actual. Vale la pena notar que entre las fuentes más populares aparece, como cabría esperar, la del diario de referencia que hemos analizado, si bien precisamente la noticia que los prosumidores han retuiteado no es la más coherente con la caracterización que priorizan las portadas de dicho diario, sino que se corresponde con la que tiene cabida en alguna columna de opinión de sus páginas interiores.

Es característico de esta red social la dominancia de voces anónimas pero populares en la red, los conocidos como "tuitstars" (en el ejemplo anterior, Alito, Superfalete o Tigretón y Bollicao), frente a las cuentas institucionales (Policía, El País o 20Minutos) e incluso a frente a las de famosos en el exterior de la red social (como el diputado Alberto Garzón, vinculado al movimiento 15M, que también figura en el ejemplo). Un rasgo característico de la comunicación de estos anónimos físicos pero superestrellas virtuales es la omnipresencia del humor y la crítica social en sus microcomunicaciones. Si en lugar de buscar el término banco, observamos el uso que en Twitter se hace de las marcas comerciales de los bancos principales, los resultados conducen a las mismas conclusiones. La siguiente tabla recoge las menciones más difundidas sobre uno de los principales bancos españoles:

\begin{tabular}{|c|c|}
\hline$@$ @ulia otero Julia Otero & @misteriodeeduca MisterioDeEducación \\
\hline pirigolzarri, se jubiló del & TupperWar a \\
\hline BBVA con 52 millones de Euros en 2009. & $\begin{array}{l}\text { Espe por posesión de dos Thermomixy una } \\
\text { batería de cocina del BBVA. A tu lado. }\end{array}$ \\
\hline & Sep 11, 2012 6:45 GMT \\
\hline \multicolumn{2}{|l|}{ @gllamazares Gaspar Llamazares } \\
\hline $\begin{array}{l}\text { El BBVA reparte acciones millonarias a sus } \\
\text { directivos y al tiempo considera insuficiente la } \\
\text { reforma laboraly los recortes. SIN } \\
\text { VERGÜENZA }\end{array}$ & $\begin{array}{l}\text { @gemmagaldon Gemma Galdon Clavell } \\
\text { Genial vinyeta Bankia a BBVA: 'Me he quedado } \\
\text { sin pasta, espera que voy a sacar dinero al } \\
\text { ciudadano automático' http://t.co/zDUgdiRd }\end{array}$ \\
\hline Apr 6, 2012 15:31 GMT & 217:27 GMT \\
\hline$@$ @iescolar & $@$ @el di \\
\hline $\begin{array}{l}\text { ¿La indemnización de Rato? Hasta 1,2 millones } \\
\text { de euros. Poca cosa. Su sustituto se llevó 52,3 } \\
\text { millones del BBVA http://t.co/dnRVrRZb } \\
\text { May 8, } 2012 \text { 0:04 GMT }\end{array}$ & $\begin{array}{l}\text { Plaza de España (Madrid), llena de } \\
\text { antidisturbios tras romper alguien el cristal de } \\
\text { un BBVA. Han disparado bolas de goma y hay } \\
\text { ambulancias. }\end{array}$ \\
\hline & Apr 20, 2012 23:47 GMT \\
\hline
\end{tabular}

Tabla V. Tuits más populares del periodo junio 2010 a noviembre 2012 conteniendo la palabra "BBVA" 
Sigue predominando la caracterización de este banco como vinculado a casos de corrupción, solapado al poder político, e incluso enfrentada al ciudadano. Estos rasgos se mantienen e incluso se agudizan para el caso de otras marcas como Bankia o Santander, que no reproduciremos por cuestión de espacio. Si no nos sorprende encontrar entre los tuits más populares los que emite el gabinete de nuestro periódico de referencia, cuya tirada ronda el medio millón de ejemplares diarios, en cambio sí que llama la atención la emergencia de aquellos portavoces de la narrativa crítica, que en su versión impresa quedan muy por debajo de esa tirada, mientras que en este espacio digital alcanzan una difusión incluso mayor que el gigante mediático Prisa. Nos referimos a Ignacio Escolar (antiguo director del diario Público) y al quincenal Diagonal.

Tenemos así una caracterización crítica del actante Destinatario de nuestra narrativa. Para poder analizar las estructuras narrativas subyacentes, deberíamos limitarnos a seguir la comunicación emitida por un tuitero concreto, o bien las que predominan en torno a un cierto hashtag (marca hipertextual de topicalización explícita utilizada en Twitter) para un periodo muy breve de tiempo, con lo que ganaríamos en coherencia y cohesión discursiva tanto como perderíamos en representatividad: la hipotética estructura resultante sería trivial en cuanto a los rasgos dominantes a medio plazo. Estas narrativas populares digitales tienen un carácter múltiple, fragmentario, son el resultado de prácticas de collage cultural, pero a juzgar por los resultados de nuestra indagación, al menos en esta red, se aproximan a las narrativas críticas antes que a la hegemónica.

Si en cambio indagamos por el resto de elementos del esquema actancial, encontraremos que el Presidente es representado la inmensa mayoría de las veces a través del humor y la ironía, como un sujeto impotente del que Europa y su pueblo se mofan, o bien ataviado de rasgos negativos como mentiroso, estafador, etc. Algunos ejemplos han aparecido ya en las tablas anteriores. Los planes de rescate bancario tampoco han sido bien recibidos en esta plaza digital: la ciudadanía digital se autorepresenta como estafada por ellos, ninguneada y apartada de la toma de decisiones. Miremos el nodo del esquema actancial que miremos, los rasgos de las narrativas "alternativas" minoritarias en el ámbito periodístico emergen como dominantes en esta red social. Detengámonos por ejemplo en el Objeto de Deseo, en torno al cual se construye todo el esquema de la narrativa justificativa de los rescates: la estabilidad bursátil, considerada por la narrativa oficial como un bien en sí mismo, de forma tan evidente que no requiere argumentación, queda al margen de toda duda. Cabría esperar en este caso quizá una mayor presencia de rasgos de la narrativa hegemónica, arracimada en torno a la nube temática que podemos asociar a la bolsa de valores, dado que este es el asunto central para los planteamientos subyacentes a esta "perspectiva del inversor", aquella que la narrativa dominante pretende naturalizar. Sin embargo, también aquí vamos a encontrar elementos de narrativas críticas. Si en el esquema actancial construido por El País, la estabilidad bursátil era el principal Objeto de Deseo, y la inestabilidad de los índices bursátiles era equiparable al "caos total" y la "hecatombe", veremos que en el universo Twitter la palabra índice se usa muy a menudo también para expresar preocupaciones, pero en general se refiere a otros índices y otras preocupaciones: 


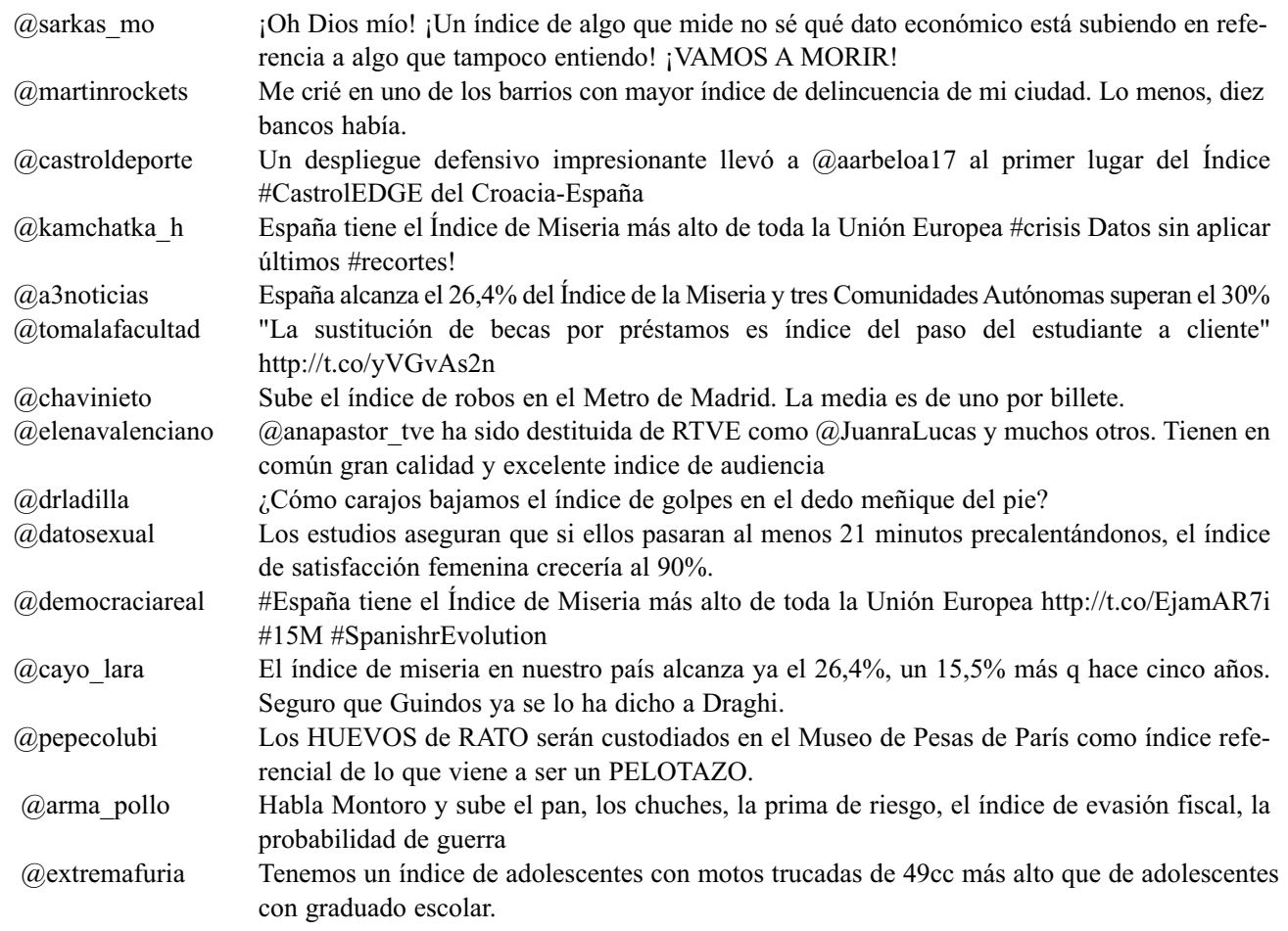

Tabla VI. Tuits más populares del periodo junio 2010 a noviembre 2012 conteniendo la palabra "índice"

Podría replicarse que en realidad la palabra "índice" no tiene por qué ir asociada al imaginario bursátil con que se construye la narración hegemónica en prensa. Sigamos buscando dicho imaginario, entonces, escogiendo índices bursátiles concretos, donde quizá sí que encontremos una dominancia de discursos tecnocráticos y economicistas, justificativos del centralismo financiero propio de la doctrina neoliberal que domina la comunicación de masas. Veamos quiénes y cómo han utilizado con mayor impacto un término técnico concreto, como "Ibex35", indicador que recoge la valoración en los mercados de las mayores empresas españolas. 


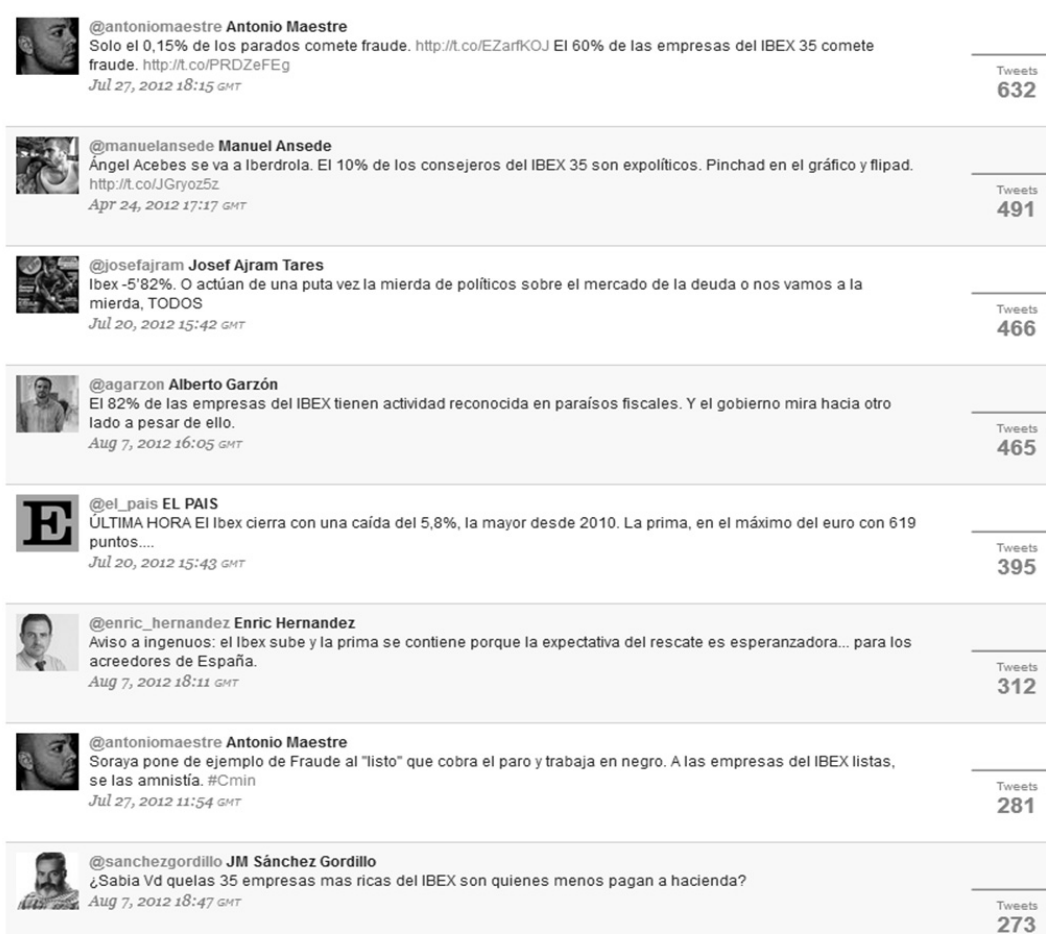

Tabla VII. Tuits más populares del periodo junio 2010 a noviembre 2012 conteniendo la palabra "IBEX"

Aquí también comprobamos, sin embargo, la dominancia del humor y la ironía que identifican estas narrativas críticas, y de las "tuitstars" que les sirven de portavoces frente a los enunciadores institucionales. Es innegable la importancia del uso de Twitter como espacio para la denuncia de corrupciones, estafas, fraude fiscal, uso de paraísos fiscales, etc. Si aquel mantra de que "la gente repite lo que oye en los medios de masas" tiene algo de cierto para algún ámbito, desde luego no es en este ágora digital.

\section{DISCUSIÓN, ENCUADRE HISTÓRICO Y CONCLUSIONES}

El auge de narrativas críticas que hacen de Twitter un espacio privilegiado para la crítica y la denuncia, como jungla virtual para la práctica de la guerrilla semiótica, tomando prestada la expresión de Umberto Eco, no debería sorprendernos si pensamos en el impacto que las redes sociales digitales han tenido sobre la estructura de los flujos de comunicación en este cambio de siglo. Ello explica la inversión de la hegemonía discursiva que hemos observado en el seguimiento transmediático de este relato de la actualidad económica.

De los esquemas unidireccionales propios de los medios de comunicación de masas del siglo XX (en realidad para masas), hemos pasado a una comunicación 
entre masas, o mejor dicho una comunicación masiva entre individuos que ocurre en el espacio público, de carácter abierto, participativo y bidireccional, incluso multidireccional, carente de centro, salvo por la propiedad paradójicamente privada del canal que la hace posible.

Sólo el tiempo revelará el alcance de esta revolución, pero el impacto que las redes sociales digitales tienen sobre el esquema comunicacional moderno no es necesariamente menor que el que tuvo la imprenta sobre el esquema medieval, y desde luego no deja intocados los flujos de comunicación masiva y por tanto tampoco las estructuras tradicionales de poder. En este sentido, conlleva una fuerte democratización del espacio massmediático, por lo que no debe sorprendernos el auge de narrativas críticas, asociadas al uso del humor y la ironía en el caso español, y utilizadas como vehículo de denuncia. Tampoco sorprende el protagonismo de ciudadanos anónimos por encima de los actores tradicionales.

Esto nos obliga una vez más a fortalecer la crítica ante algunos de esos axiomas repetidos incluso en ambientes académicos, acerca de una supuesta creencia y repetición de los discursos masivos por parte de las audiencias. Que muchas comunidades hermenéuticas compartan en gran medida los imaginarios construidos por la televisión de masas en absoluto quiere decir que otorguen legitimidad o credibilidad alguna a la información que esta les sirve, ni tampoco a las narrativas y caracterizaciones que su discurso construye. No sólo el espectador del siglo XXI ya no reproduce acríticamente lo que recibe, si es que alguna vez esto ocurrió, sino que además debemos quizá empezar a abandonar definitivamente la noción misma de "espectador" (que espera la recepción de un discurso) a favor de una serie de roles fundamentalmente activos no sólo como interpretante, sino como mediador cultural activo, como diversos modelos en comunicación de masas vienen sugiriendo, e incluso como verdadero prosumidor con carácter realmente protagonista en la producción de contenidos en el esquema comunicacional nacido de la red de redes.

\section{BIBLIOGRAFÍA}

Almirón, N., (2008). "El deute de Sogecable i Prisa". Quaderns del CAC, vol. 29, Regulación y cambio en el audiovisual, septiembre-diciembre 2007. pp. 105-116.

-, (2009). "Grupos privados propietarios de medios de comunicación en España: principales datos estructurales y financieros". Comunicación y sociedad, vol. 22 (1), pp.243-273.

Almiron, N. y Segovia, A., (2012): "Financialization, Economic Crisis, and Corporate Strategies in Top Media Companies: The Case of Grupo Prisa". International Journal of Communication, 6, pp. 2894-2917.

BRUns, A. y BuRgESS, J.E., (2011). "New methodologies for researching news discussion on Twitter.” En The Future of Journalism 2011. Cardiff University, Cardiff, UK. Disponible en: http://eprints.qut.edu.au/46330 [Accedido el 29 de abril de 2013].

COURTÉs, J., (1997). Análisis semiótico del discurso: del enunciado a la enunciación. Madrid, Gredos.

—, (1980). Introducción a la semiótica narrativa y discursiva. Buenos Aires, Hachette. 
LeOnE, M., (2013). "Héroes y antihéroes trans-textuales: el caso Kony 2012”. En coloquio Narrativas transmediáticas y construcción de los asuntos públicos. Universidad Complutense de Madrid, 4 de febrero de 2013 (publicado en CIC Cuadernos de Información y Comunicación 19, 2014).

Williams, R., (2003). Palabras clave: un vocabulario de la cultura y la sociedad. Buenos Aires, Nueva Visión.

\title{
RESUMEN
}

Los principales periódicos españoles, como es el caso de El País, enmarcaron desde un principio la presente crisis económica a través de la "metáfora del desastre natural", identificando la supervivencia de la banca privada con el bien común, y por tanto el desvío de fondos públicos para su rescate como una opción técnicamente necesaria, al margen de posicionamientos políticos. Si indagamos los relatos hegemónicos en el espacio digital de Twitter, encontraremos en cambio construcciones narrativas mucho más cercanas a los discursos críticos minoritarios en periodismo, propios de periódicos alternativos de pequeña tirada.

Palabras clave: Transmediático, narratividad, crisis, análisis del discurso, medios de comunicación, Twitter.

\section{Discursive hegemony in the transmedia story of the crisis: digital narratives vs journalism}

\begin{abstract}
Spanish main journals, such as El Pais, have framed the subprime financial crisis through the "natural disaster metaphor", identifying the survival of the private banks with the common good. The use of public funding for private bailouts was presented as a non-ideological technical solution, extern to political discussions. Nevertheless, having a look at the hegemonic narratives in the Twitter digital agora, we find a very different kind of constructions, much closer to the alternative discourses from minor journals, criticizing the bailout politics.
\end{abstract}

Keywords: Transmedia, narrative, crisis, discourse analysis, mass media, Twitter. 